الأشغال الفنية بين الخامات البيئية و متفيرات العصر

اعلداد

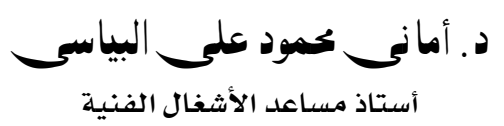

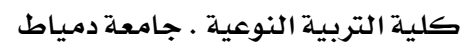

مجلة بحوث التربية النوعية ـ جامعة المنصورة

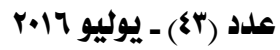




\section{الأشغال الفنية بين الخاهات البيئية و متغيرات العصر}

إعداد

*

د. أمانرممود على البياست

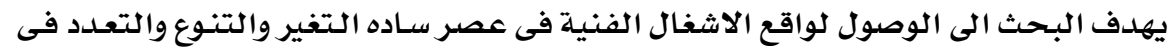

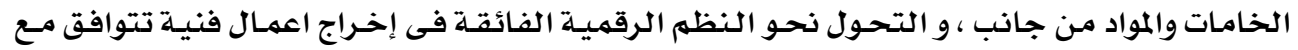

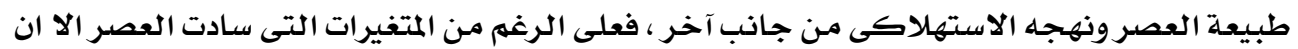

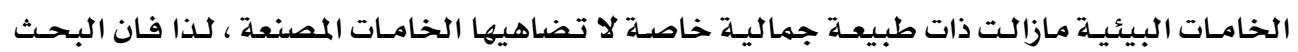

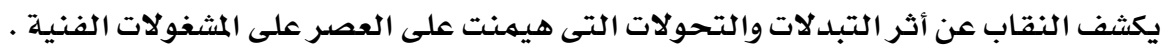

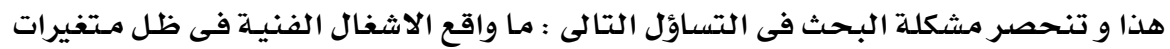

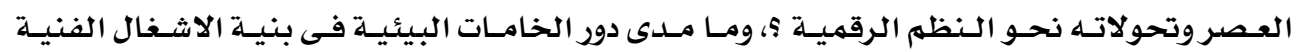

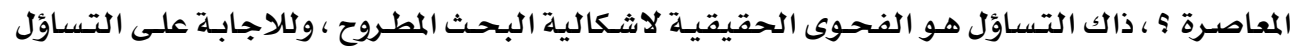

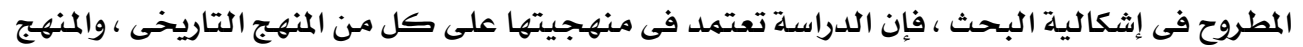
الوصفى التحليلى .

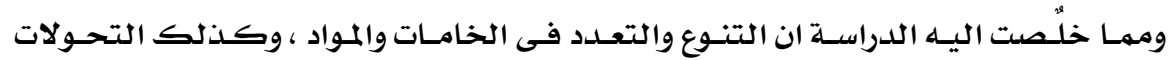

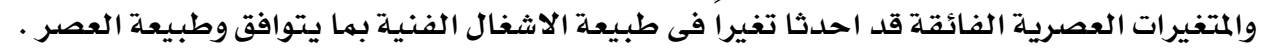
الكلمات المفتاحية : الاشغال الفنية ، الخامات البيئية ، متغيرات العصر .

مقدهمة : مقدم

تُعد الاشغال الفنية Handicraft احد نظم التشكيل الفنى التى تحوى قيم فنيـة وجماليـة

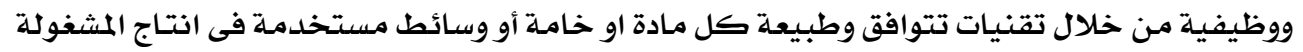

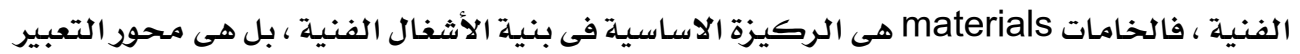

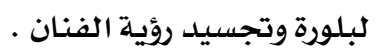

ولما كانت الأثـال الفنيـة كيـان فنى قائم على أسس فنيـة وتقنيـة ، وتبحث عن الجمال

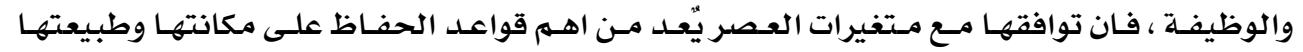

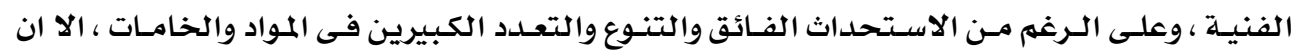

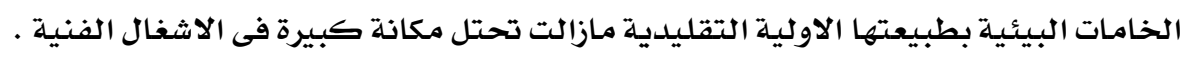

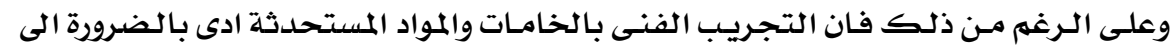

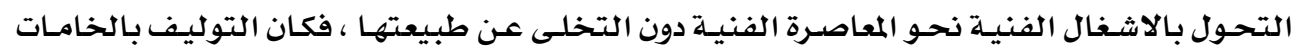




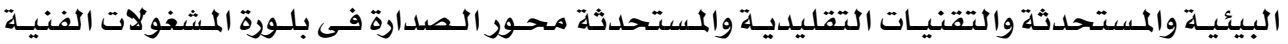

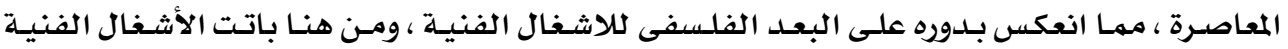

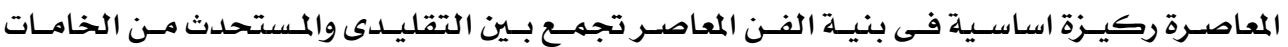

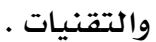

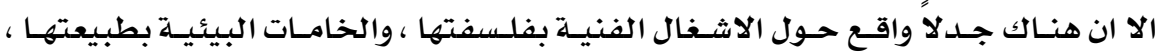

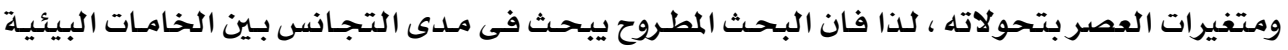

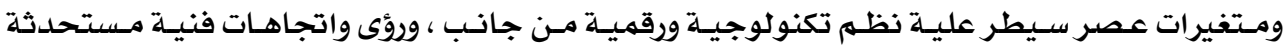

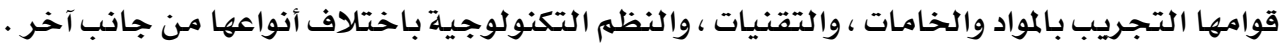

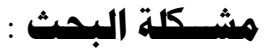

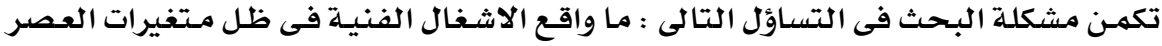

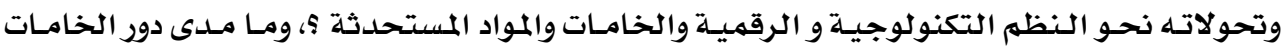

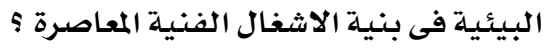

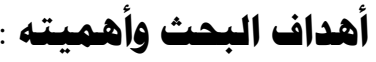
يكمن هدف البحث وكذلك أهميته فى التالى :

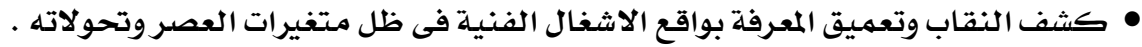

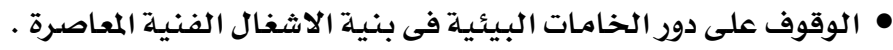

$$
\text { تكمن فروض البحث يْ التالى : }
$$

• ان متغيرات العصر بتفوقه التكنولوجى والرقهى ساعدت في أثراء الاشغال الفنية المعاصرة

$$
\text { وتطورها . }
$$

• ان للخامات والمواد البيئية دور فاعل فى بنية الأشغال الفنية المعاصرة على الرغم من

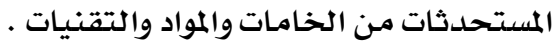

فى محاولة للاجابة على التساؤل المطروح والذى يمثل مشكلة البحث فإن البحث يعتمد فى منهجيته على المنهجين التاليين : ماتهانه

$$
\text { • • المنهج التاريخى • }
$$

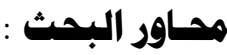

تنحصر محاور البحث فى التالى :

• ماهية الاشغال الفنية وطبيعتها.

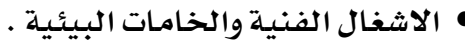




$$
\text { • • الاثغال الفنية ومتغيرات العصر • النتائج والتوصيات ، المراجع • }
$$

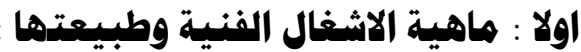

فى واقع الأمر فان الحكمة الجدلية لفلسفة الاشغال الفنية تكمن فى مدى تحقيق

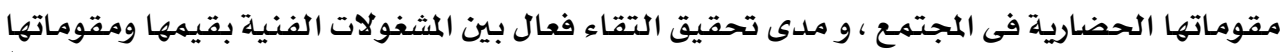

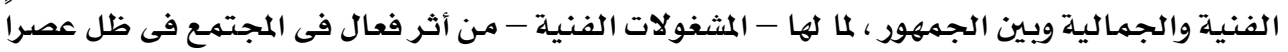

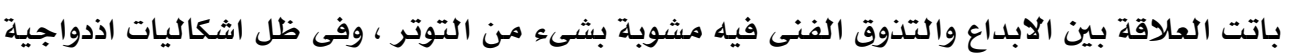

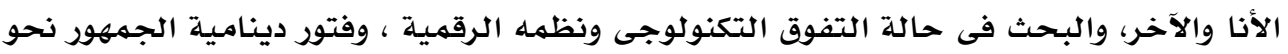

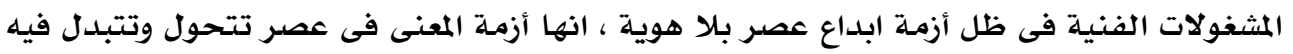

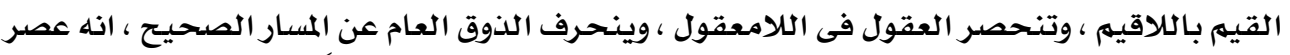

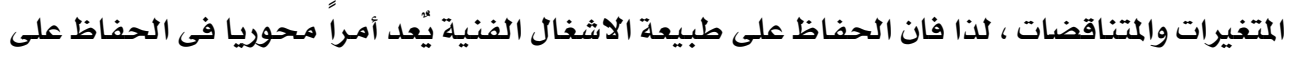

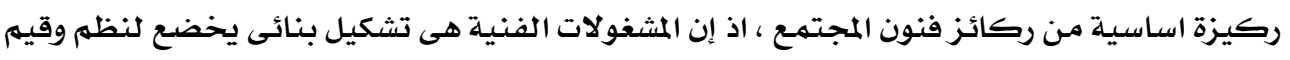

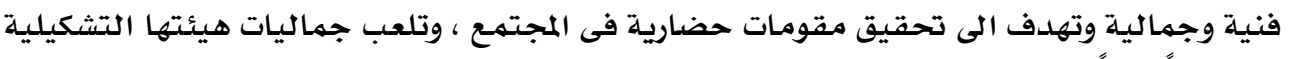

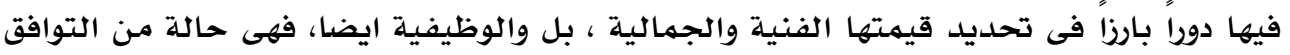

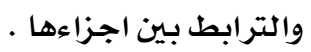

إن طبيعة الاشغال الفنية تحوى بين جنباتها عمق عملية الإبداع الفنى بمقوماتها المختلفة

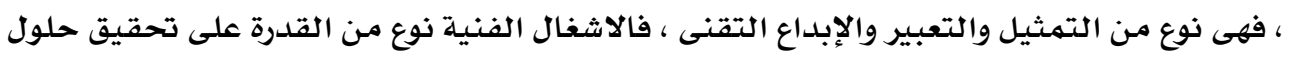

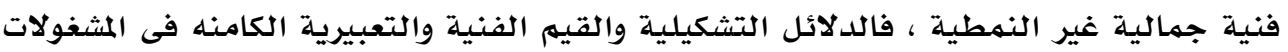

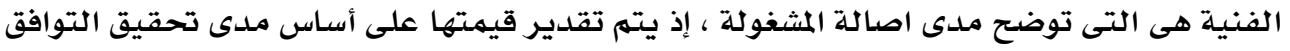

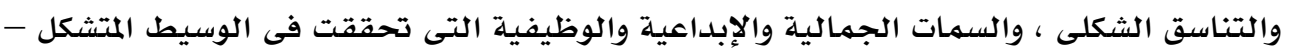

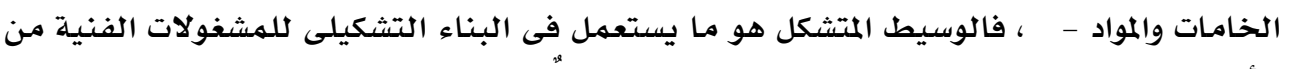

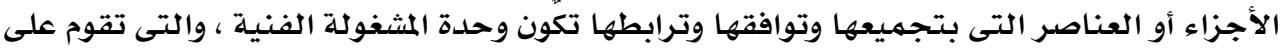

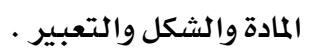

لما كانت مادة المشغولة الفنية هى وجها المحسوس ، فهى أبسط عناصرها ، كما أنها

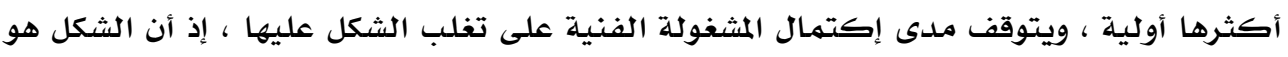

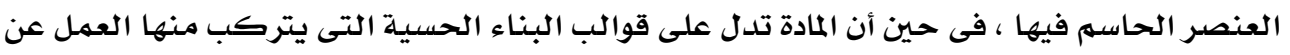

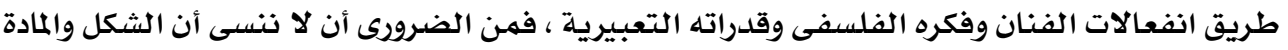

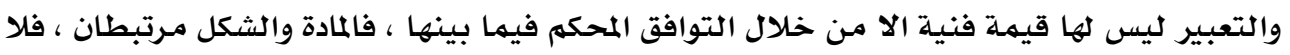

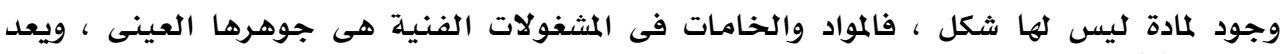

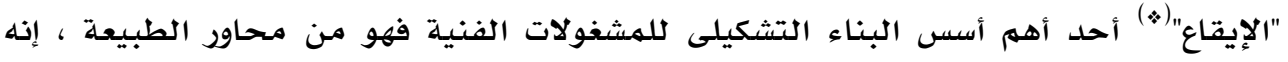

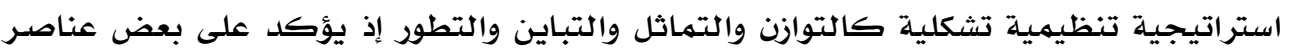


العمل وعلاقاتها بأخرى ، هذا إلى جانب أنه سمة زمانية فى الفن التثكيلى ، كما أنه يشيع فى ذي

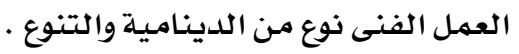

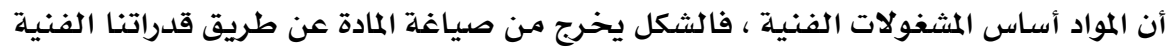

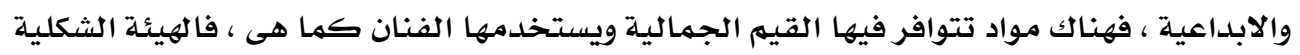

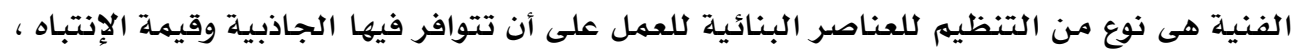

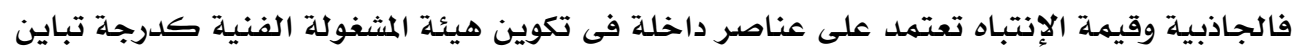

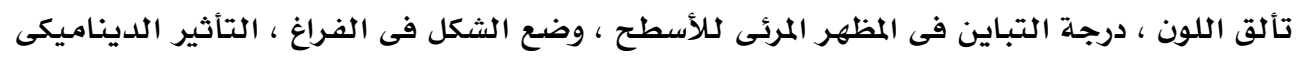

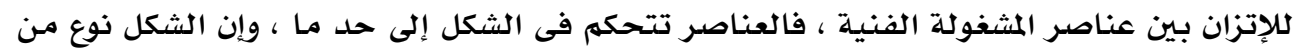

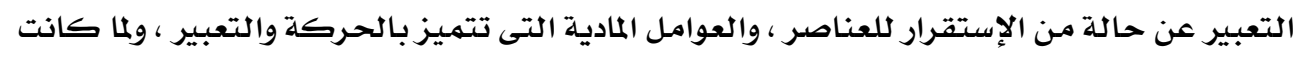

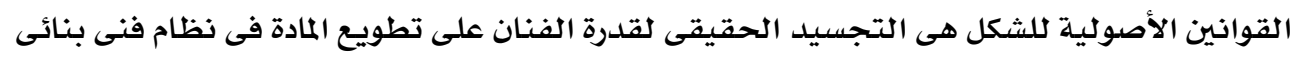

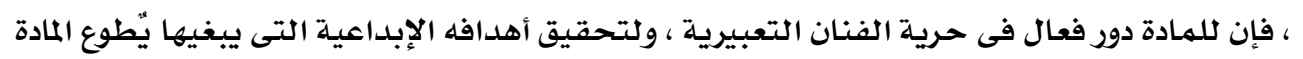

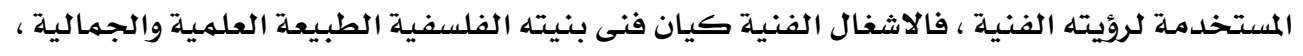

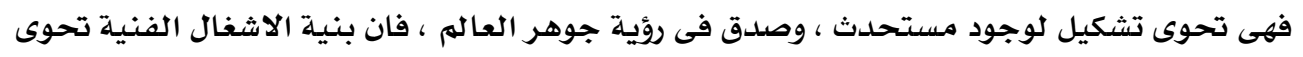

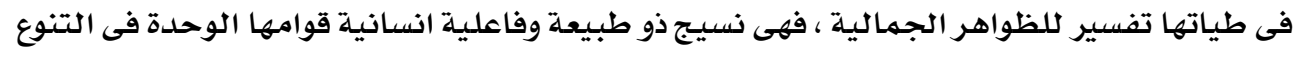

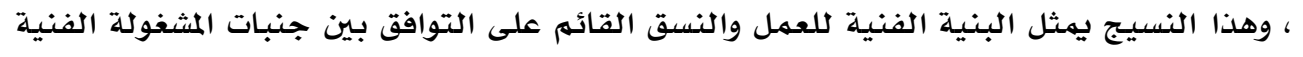

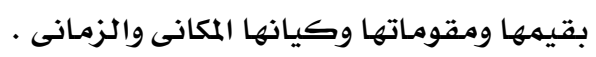
وعلى الرغم من ان المادة والشكل والمضمهون التعبيرى ثوابت فى بنية الاشغال الفنية ، الا انها

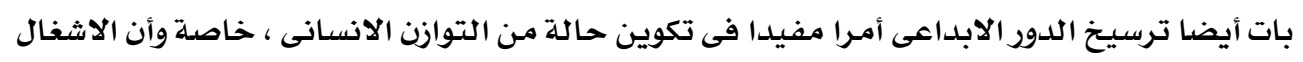

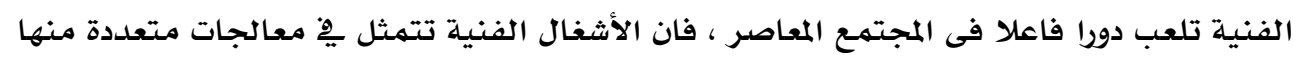

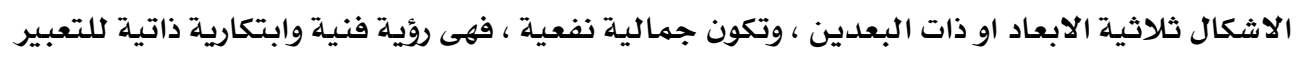

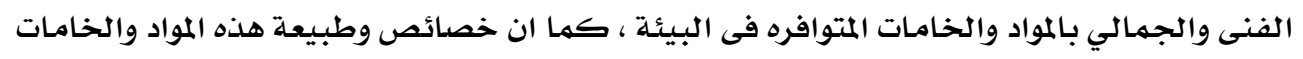

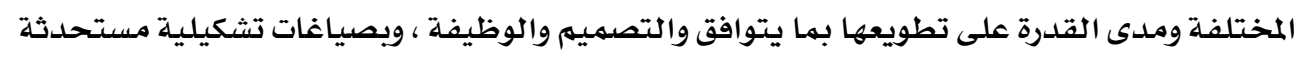

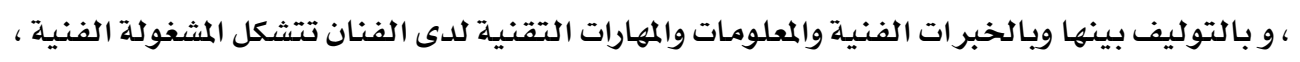

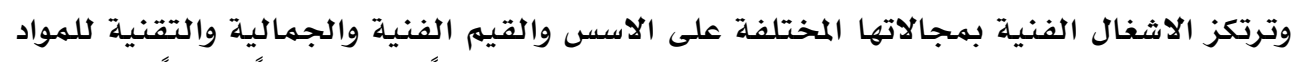

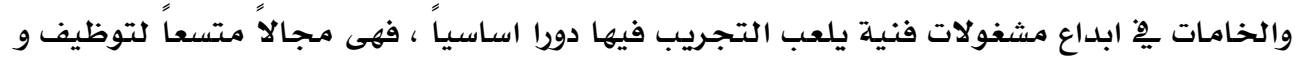

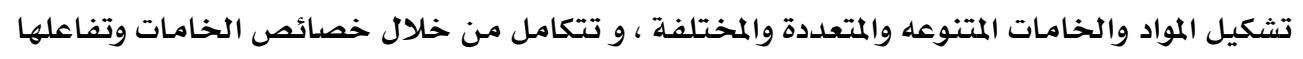

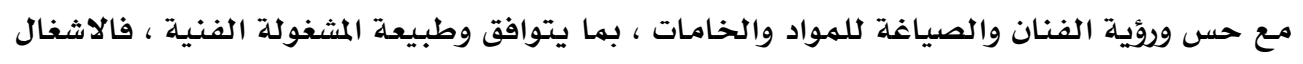

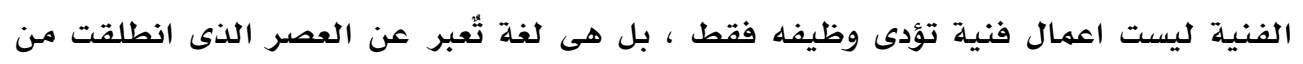
بين جنبـاته .

بالرغم من أن طبيعة الاشغال الفنية والسمات المميزة للجيد منها تحوى بين جنباتها الدقة

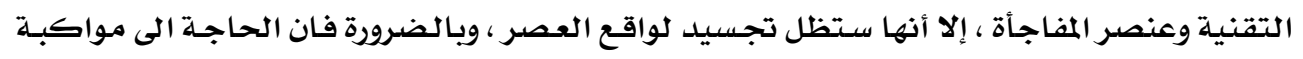

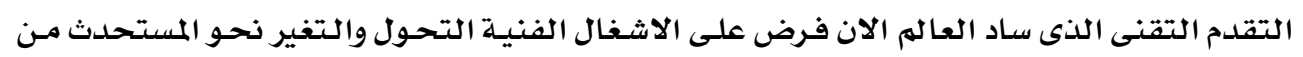


المواد والخامـات مـن جانب ، والتحـول التقنسى مـن جانب آخـر ، فعصرنا تميـز بسـمة الإيغالـة في دنيا

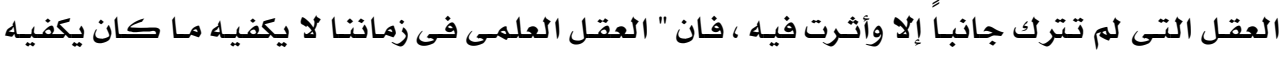

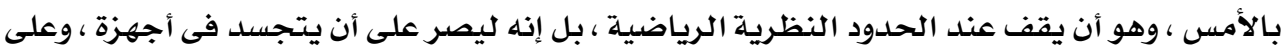

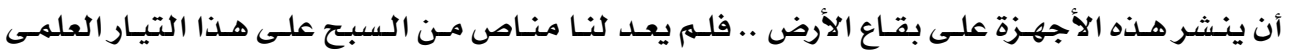

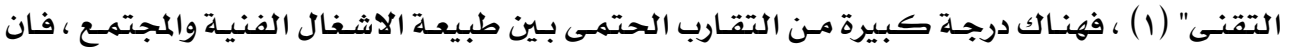

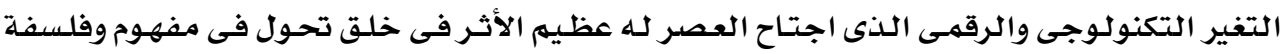

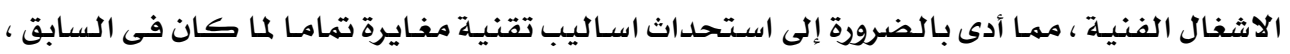

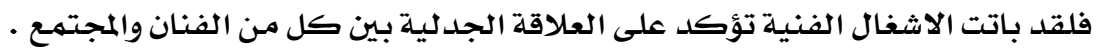

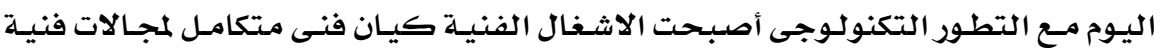

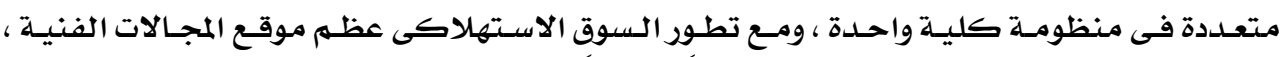

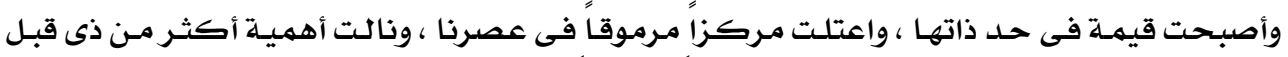

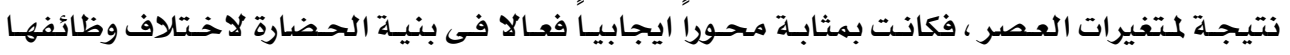

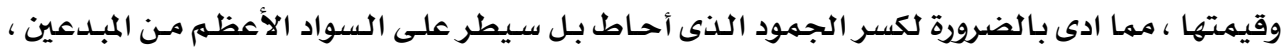

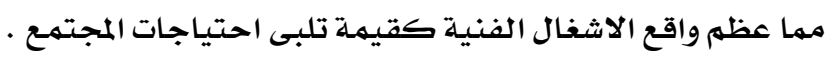

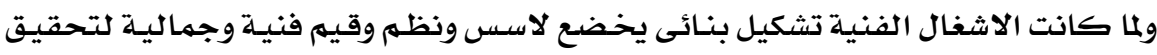

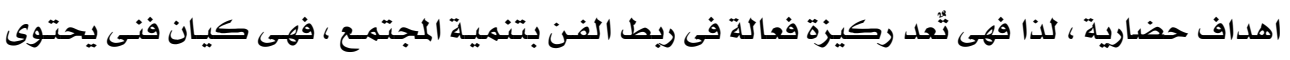

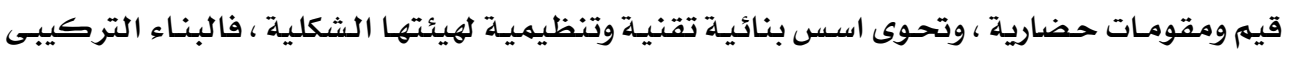

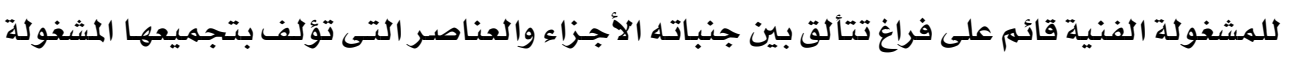

\section{من هنا نستخلص التالى :}

• إن فلسفة الاشغال الفنية المعاصرة خلقت لذاتها نوع مـن المفهوم المؤكد على استقلالالها فنياً ،

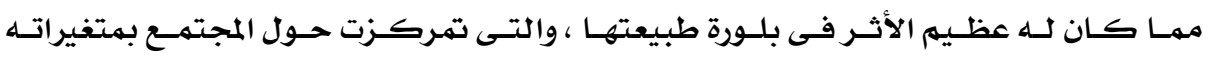

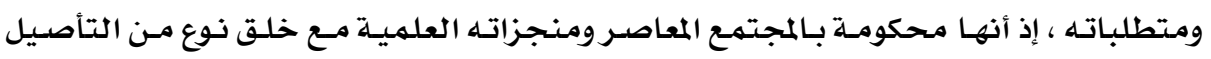

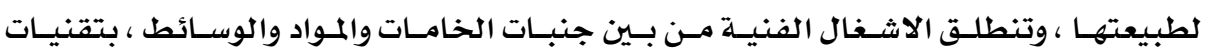

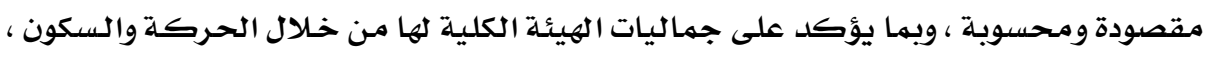

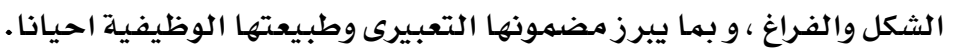

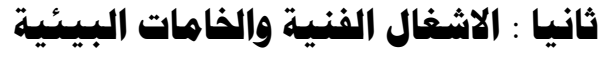

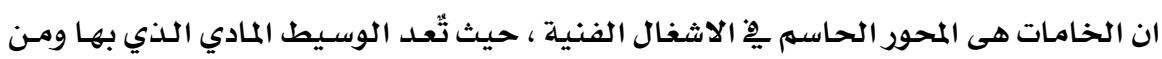

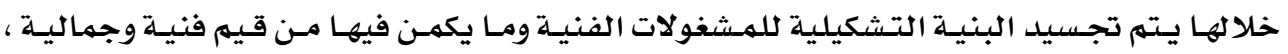

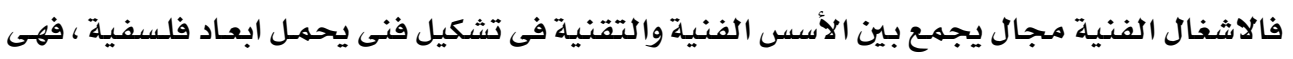

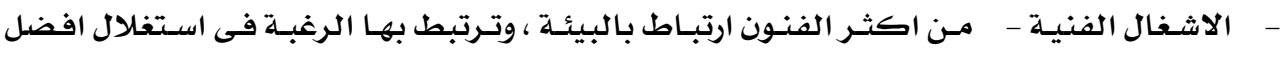

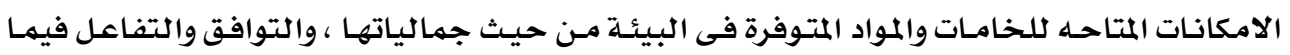


بينها وبين احاسيس ورؤية الفنان لخلق عمل فنى يقوم على القيم الفنية والجمالية ، وما يتطلبـه مـن

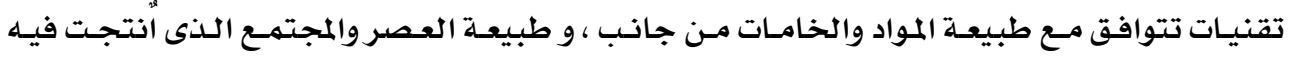

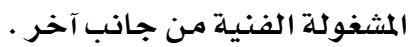

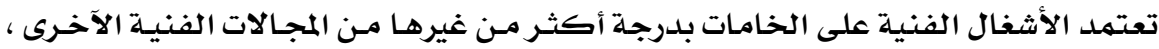

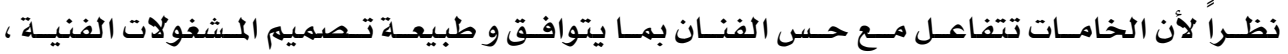

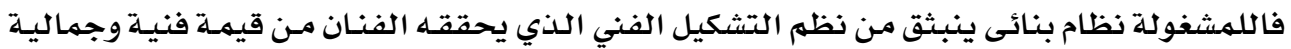

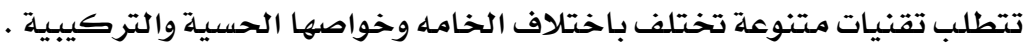

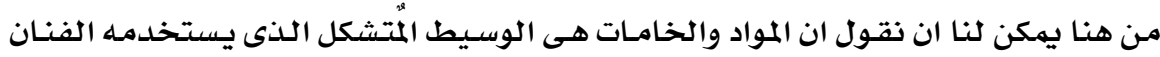

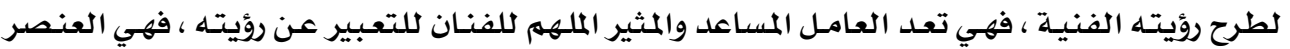

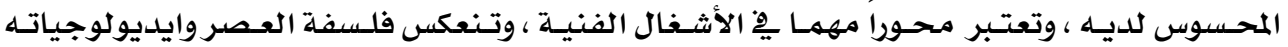

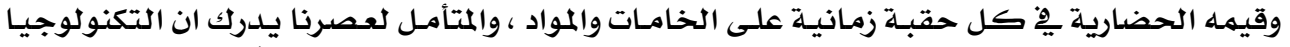

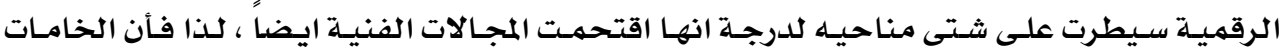

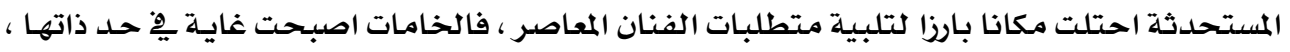

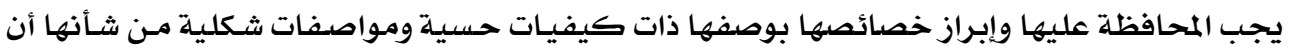

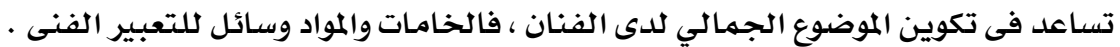

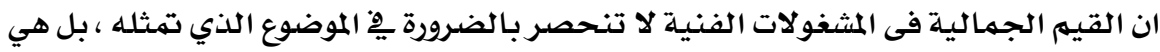

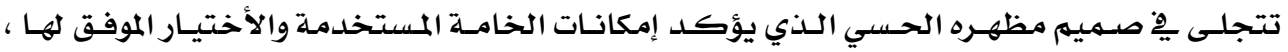

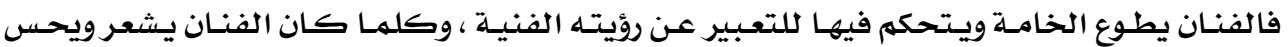

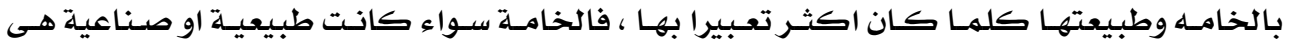

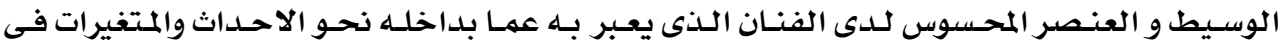

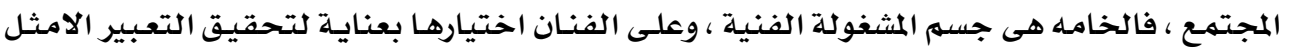

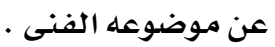

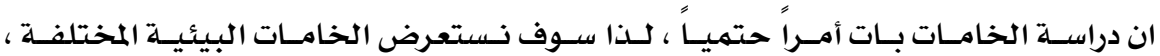

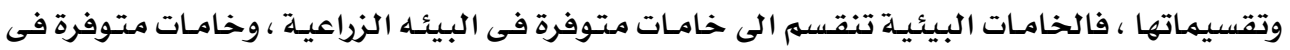

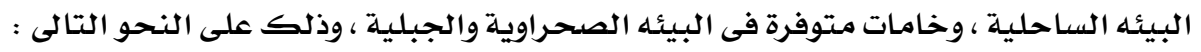

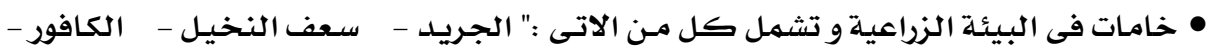

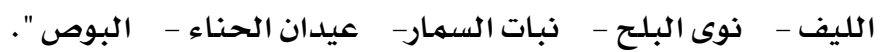

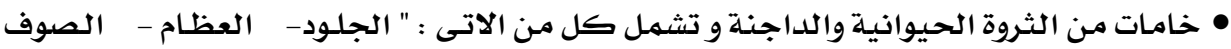

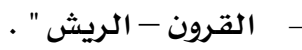

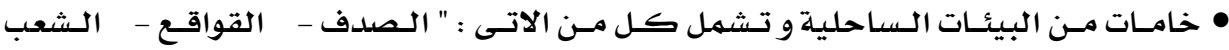

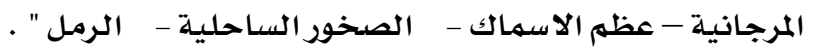




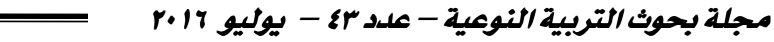

• خامـات فى البيئـه الصحراوية و الجبليـة و تشمل كل من الاتى : " الاشجسار البريـة - الصخورو

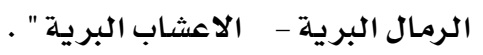

ان الخـامـات السـابقة هـى الاكثـر شـيوعا فـى الاشـغال الفنيــة بـصورها التقليديـة ، الا ان

متغير ات العصـر ادت الى اسـتحداث مـواد وخـامـات جــيـدة ذات خـواص حسية وتركيبيـة مغـايرة تمامـا

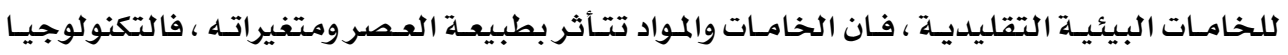

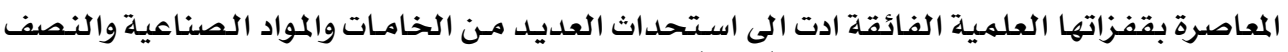
صناعية ، والتى سـرعان مـا اتخـذت موقعـا هامـا فى بنيـة متطلبـاتنـا المعاصـرة فى شـتى المجـالات ومنهـا الفنون ، تلك التى تأثرت بقوة بـالتكنولوجيا وما نتج عنهـا مـن مـواد وخامـات وعوامل آخـرى ، فاليوم يتمم استخدام الاجهزه الاككترونيـة والتقنيـات الرقميـة الحديثـة كهـواد وخامـات ووسـائط لطرح رؤيـة

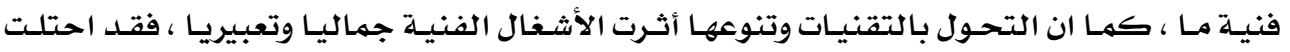

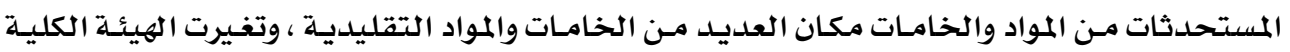
للاعمال الفنيـة ومنها الاشغال الفنيـة ، بل تعددت وتنوعت أكثر وأكثر بـايـة مسن الشكل وصسولا الى المضمون ، وظهر بقوة التركيب والتجميع فى المشغولات الفنية ، بل بالأحرى التوليف ، مـع استحداث

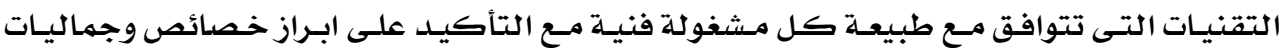

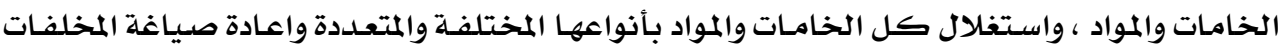
والمستهلك منها ايضا فى ابتكار اشغال فنية معاصـرة ، مها كان له عظيهم الأثر فى التحول بالاشغال

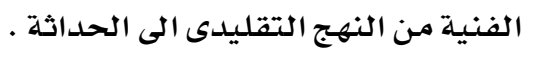

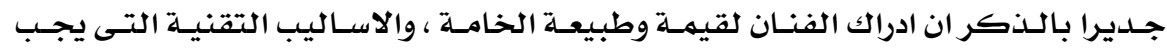

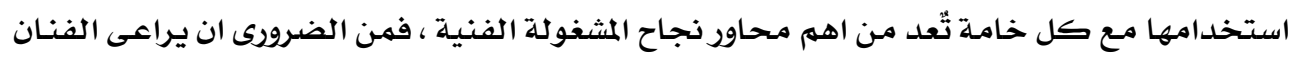
يِّ اختيار خامـاته ما يـلى :

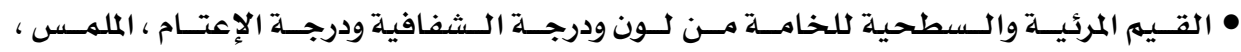
المظهر الخارجى. • الخواص الكيميائيـة والفيزيائية والميكانيكية للخحامـة .

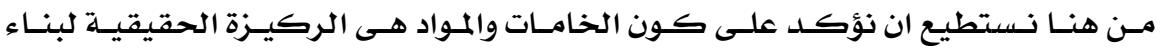
مشغولات فنية ، لما تتمتع بـه مـن خواص حسية وتركيبيـة ، و ابعـاد جماليـة وفلسفيـة تتطلسب اسـاليب تقنية لطرح الرؤيلة الفنيـة والتأكيد على الابعاد الوظيفيـة للمشغولية الفنيـة ، ومـا تتضمنهـ مـن قيهم تشكيليـة ومضامـين تعبيريـة ، اذ ان الخامـات تُعد كيان من الوسـائط المتتوعة التى يستغلها الفنـان فى عمله التشكيلى ليخلق المقوم الحضارى للعهل الفنى وذلك لكونها تُعدل التالى : لكيلى

$$
\begin{aligned}
& \text { • وسيط حســـي • } \\
& \text { • وسيط تقني جمالي • } \\
& \text { • وسيط بنائي • } \\
& \text { • وسيط رمـزى . }
\end{aligned}
$$




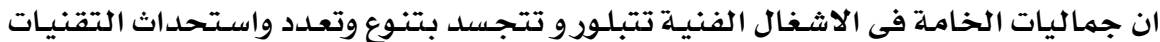

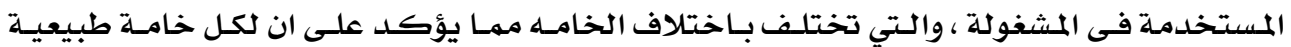

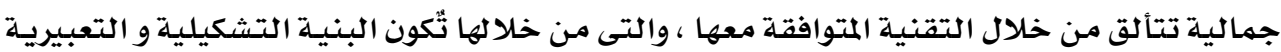

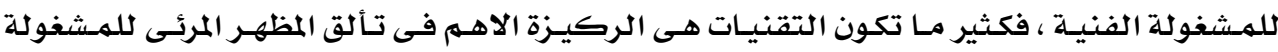

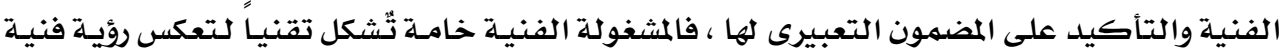

$$
\text { ذات طبيعة تعبيريـه محلددة . }
$$

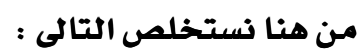

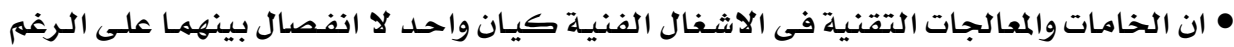

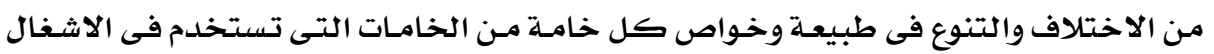

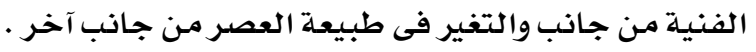

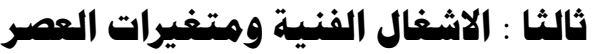

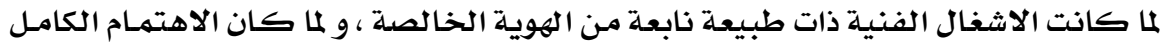

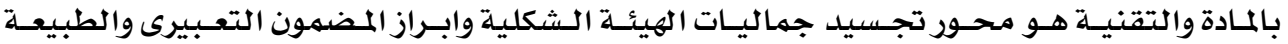

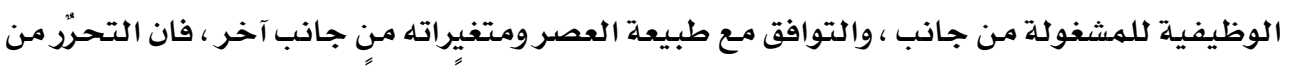

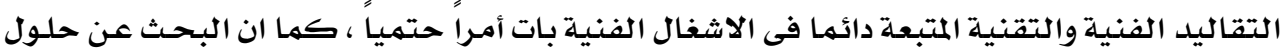

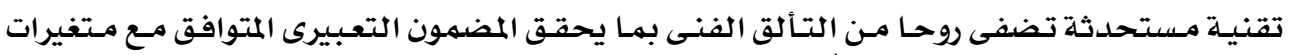

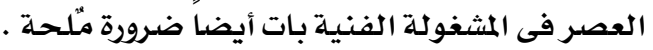

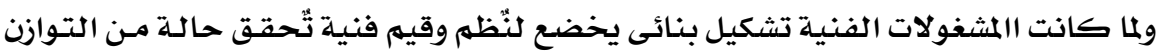

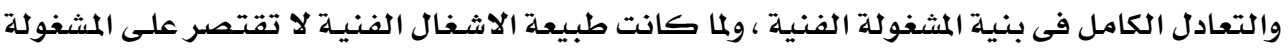

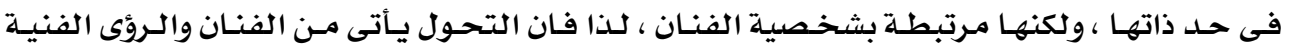

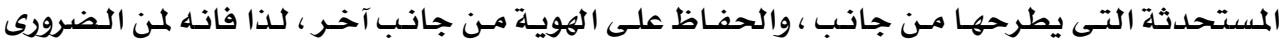

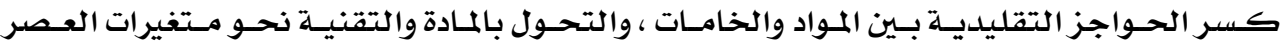

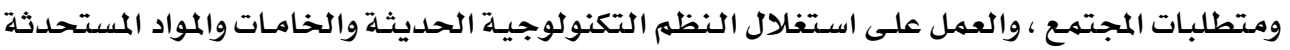

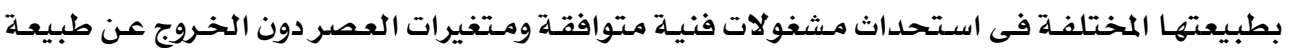

الاشغال الفنيلة وخصائصها وهويتها.

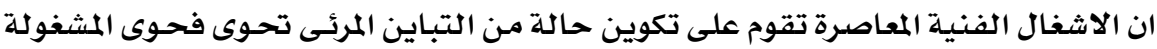

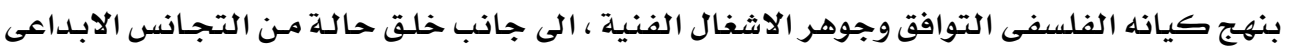

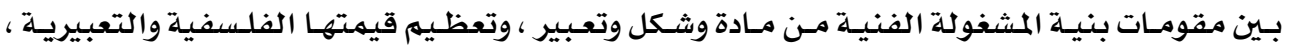

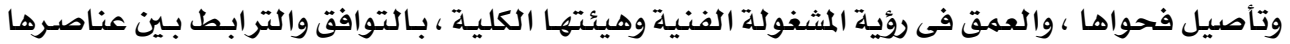

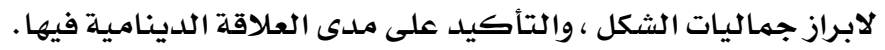


ان تحقيق نوعاً من التطور الإيجـابى فى الاشغال الفنيـة يتطلب التعبير عن الفكر الإبـداعى

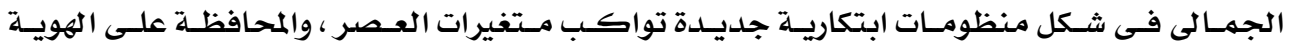
وتأصسيلها وحمايتهـا مـن الغـزو الثقـافى المتزايــ فى ظـل التفـوق الرقهـى الكاسـح ، تحقيـق نـوع مـن الارتقاء فى شكل المشغولة الفنية وتسخير تكنولوجيا العصر لتطويرها .

ان قيمـة الاشغال الفنية تنبـع من التفوق فى كيانها وآلياتها وانسـاقها الفنيـة المؤكدة على ابراز جماليـات الخامـات والدقة التقنية كعوامل محوريـة فعالة فى بنيتها ، وتلـك العوامل لهـا اسسس فنية وفلسفية تضع قواعدها البنائيـة ، ونابعة مـن قدرات الفنان ، والتى تتضهمن العديــ مـن الجوانب ، والتى تقوم على الادراك المميز ، والاحسـاس المتفاعل مـع الظواهر وادراك قيمتها فى المساهمـة فى خلقى في

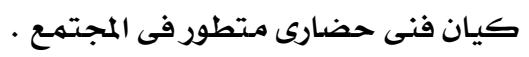
إن المنطـق المحكـوم بقواعـد موضـوعيـة للجـوانب العلهيـة والفنـيـة فـى الاشـغال الفنيـة مـن الضرورى ان يتوافق والاحسـاس بمدى عمق الحـاجـة الحقيقيـة اليها فى المجتمـع ، والاحسساس بـدورها

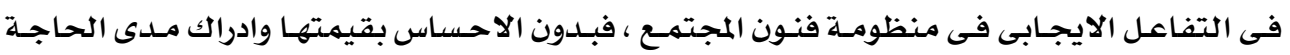
اليها كركيزة فعالة فى بنيـة فنون المجتهـع ، لن يكون هنالك توافق ومتغيرات العصر ،

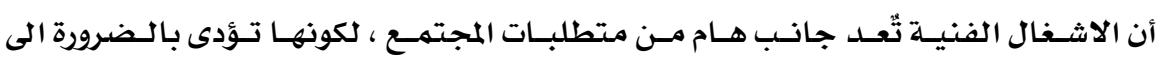

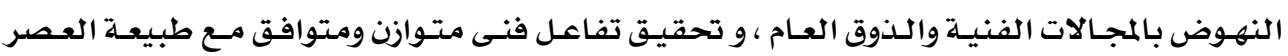

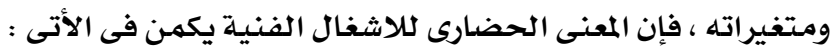

• مـلـى التفـوق القيهـى فـى المشغولات الفنيـة ودقتهـا التقنيـة وارتبـاطها بـالظواهر الاجتمهاعيـة

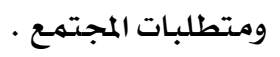

• ان البناء الحضـارى لطبيعة الاشغال الفنية يحوى بـين ثنايـاه نوع مـن الاتحـاد الكلى للعديد مـن

المجالات الفنية المختلفة بنظم تقنية متوافقة مـع التغير شبـه الدائم الذى يسود العصر.

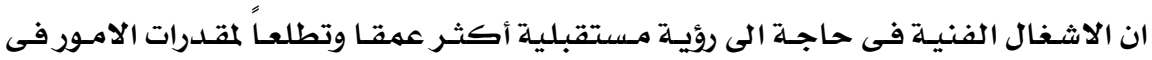
المستقبل ، والتأكيـد على دورهـا المستقبلى فى المجتمهع المعاصـر مـن خـلال اسـس معياريـة وكيانـات بنائية تقوم عليها والتى تنحصر في الأتى : • ان الاشـال الفنيـة تهثل كيـان اقتصـادى يهكن تطـويره كصنـاعات صـيرة تتوافق وامكانـات

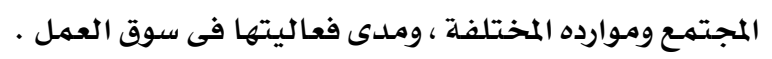

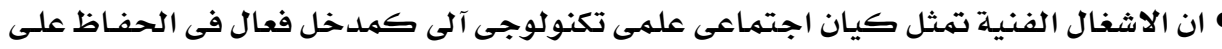

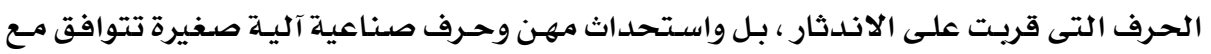

$$
\text { متغيرات العصر والتطور التكنولوجى الفائق . }
$$

إن هذه الكيانات ستؤدى بالضرورة الى خلق روح مـن التفاعل الحضـارى بـين الاشـخال الفنيـة 
مـن هنـا فـان المحافظـة على طبيعـة الاشغخال الفنيـة وتوافقها مــع مـتغيرات العـصر يجـب ان تقوم على الركائز التادية:

• الدمـج بين الخامات والمواد والمعالجات التقنية التقليدية والمستحدثة ، والمحافظلة على طبيعتها بتألق مكنون جمالياتها بـانسـاق وصياغات تشكيلية ابداعية وتقنية جديدة ، بها يتوافق وطبيعـة متغيرات العصر ومتطلباته والحركاته الفنية السـائدة . • استحداث صياغات تشكيلية مليئـة بـانفعـالات مبتكريها مـن جانب ، والجماليـات المتوافقـة التى تعكس مدى حيويتها من جـانب آخر .

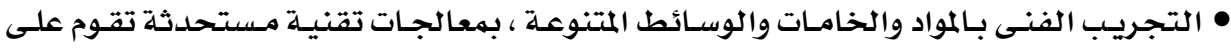

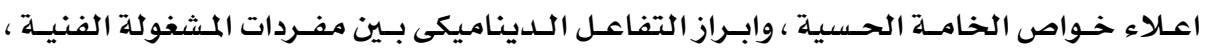

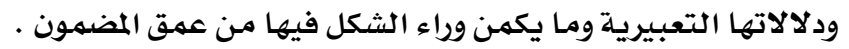

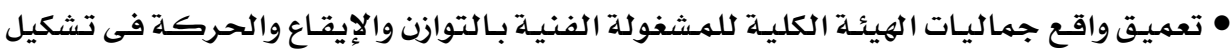

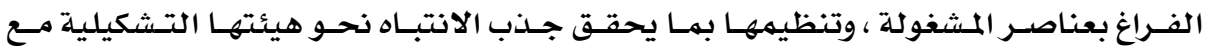
التأكيد على عمق الارتباط بجمالياتها وتوافقها مـع متغيرات العصر . من هنا نستخلم التالى :

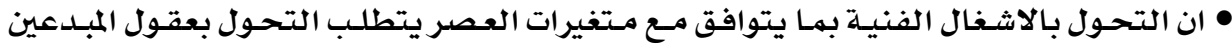
نحو التجريب والتوافق مـع طبيعـة العصر ومتغيراته مـن جانب ، والتوافق مـع الحركـات الفنيـة المعاصرة من جانب ثانى ، والثبات بل الحفاظ على هوية وطبيعة الاثغال الفنيـة مـن جانب آخر.

رابعا : النتتائج :

من الطرح السـابق خلصت الدراسلة الى النتائج التالية : • ان ماهية الاشـال الفنيـة فى عصر المتغيرات تكمـن فى البحـث المطلق اللازمنسى لفلسفة فنـون

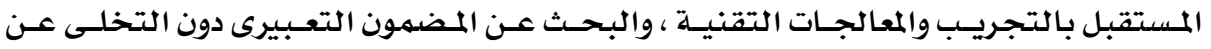
الشكلانيـة ، وعمق العلاقة الجدلية الكامنـه فى المشغولة الفنيـة ، بهواد وخـامـات بيئيسة تقليديـة

$$
\text { وآخرى مستحدثة ، وبأسس جمالية لامتتـاهية التعقيد . }
$$

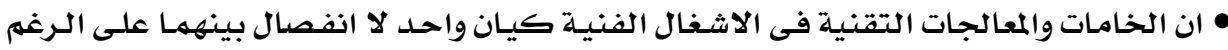

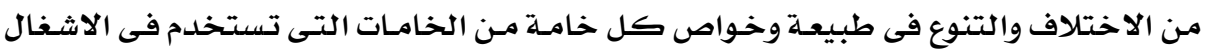

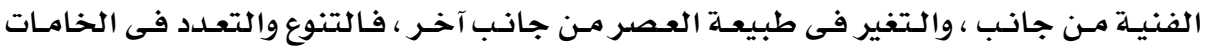
والمواد البيئية والمستحدثة ، وكذلك التحولات والمتغيرات العصرية الفائقة قد احدثا تغيرا فى طبيعـة الاثغال الفنيـة بما يتوافق و طبيعة العصر ومتتغيراته ، اذ تنطلق الاشغال الفنية مـن بين

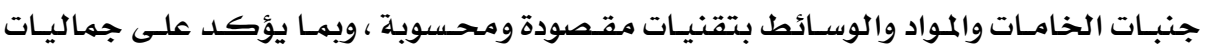

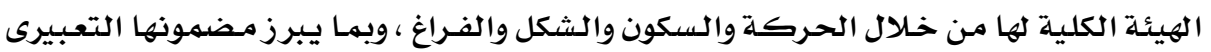
وطبيعتها الوظيفية احيانا، الا ان الخامات البيئية ظلت ذات مكانة رئيسية فى الاشغال الفنية. 
• إن فلسفة الاشغال الفنية المعاصرة خلقت لذاتها نوع مـن المفهوم المؤكد على استقلالها فنيـاً ،

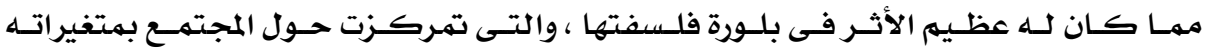

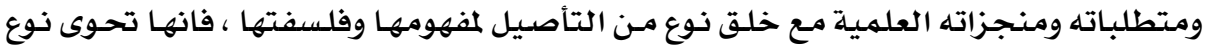

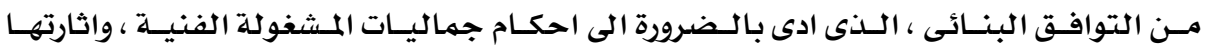

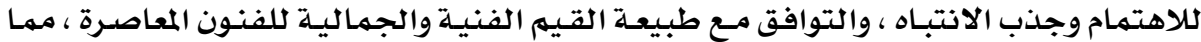

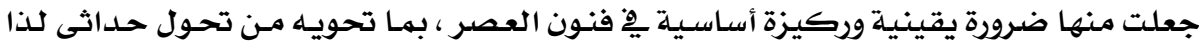

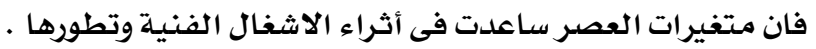

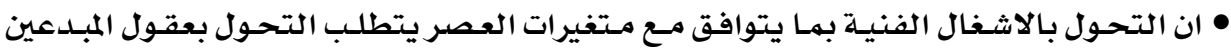

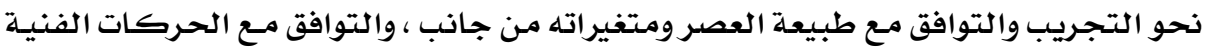

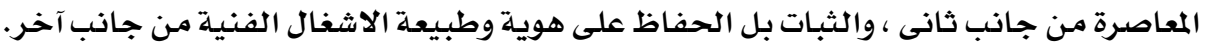

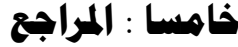

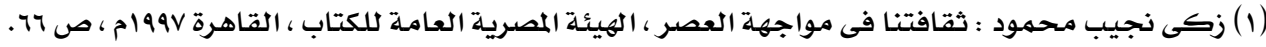

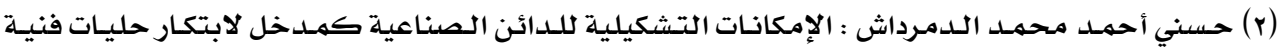

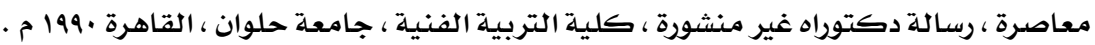

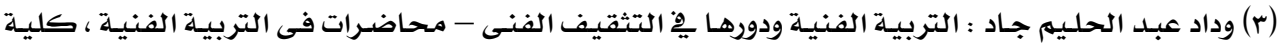

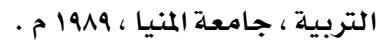

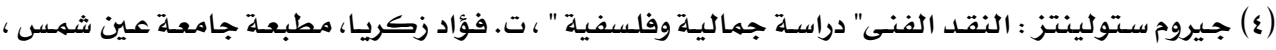

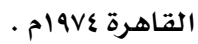
(0) سيوناير روبرتسون : الاشغال الفنية والثقافة المعاصرة ، ت ـ محمد خليفة بركات ، الهيئسة المصرية العامـة

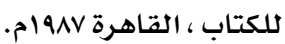
( ( ) آرنست فيشر : ضرورة الفن ، ت. أسعد حليه ، الهيئة المصرية العامة للكتاب ، القاهرة ، 1991 ام .

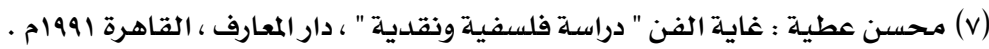

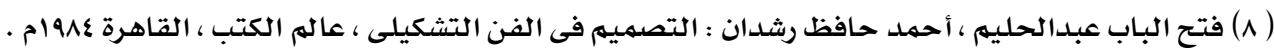

\section{سادسا : الحواشى كما وردت في الدراسة :}

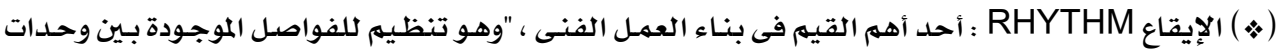

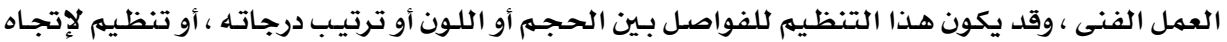

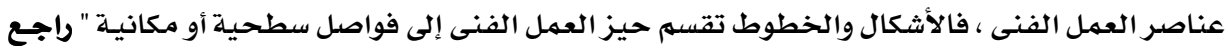

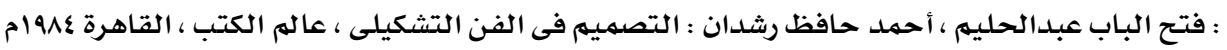

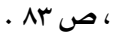

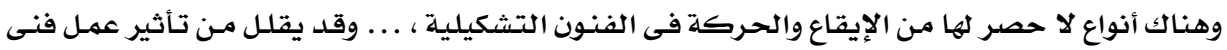

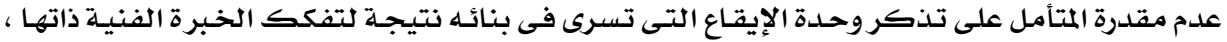

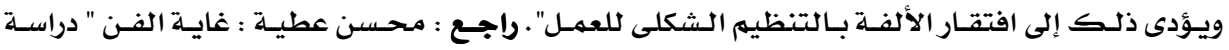

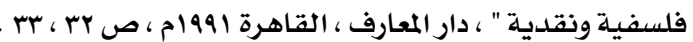




\section{Handicraft between environmental materials \\ and Contemporary changes Preparation}

Amani Mahmoud Ali El Biasi*

\section{Abstract}

The research aims to reach the reality of the art works in the Plain of change and diversity and plurality in the raw materials of the era, and the shift towards high -digital systems in the output of artwork are compatible with the nature of the times and his approach consumer on the other hand, although the variables that dominated the era, but the environmental ores still particularly unmatched raw materials manufacturer of aesthetic nature, so the search reveals the impact of changes and transformations that have dominated the era handicrafts.

This and confined to the research problem in question follows: What is the reality artistic works under the contemporary changes and transformations towards digital systems?, And how the role of environmental materials in handicraft contemporary architecture?, That is the real question of the problematic search before tenor, and the answer to the question posed in the problem of the research, the study is based on the methodology of each of the historical approach, and the descriptive analytical method.

It was concluded by the study that diversity and plurality in the raw materials, as well as transitions and modern variants super Ahdtha may change in the nature of the handicraft, consistent with the nature of the times.

Keywords: handicraft, environmental materials, contemporary changes.

*Handicraft assistant professor. Faculty of Specific Education. Damietta University 